DEPARTAMENTO DE ZOOLOGIA - LAB. DE FISIOLOGIA GERAL E ANIMAL (Prof. P. SAWAYA)

\title{
Respostas dos Melanóforos de Traíra (Hoplias malabaricus) a vários excitantes
}

\author{
por \\ Erasmo G. Mendes
}

1.- Assistente

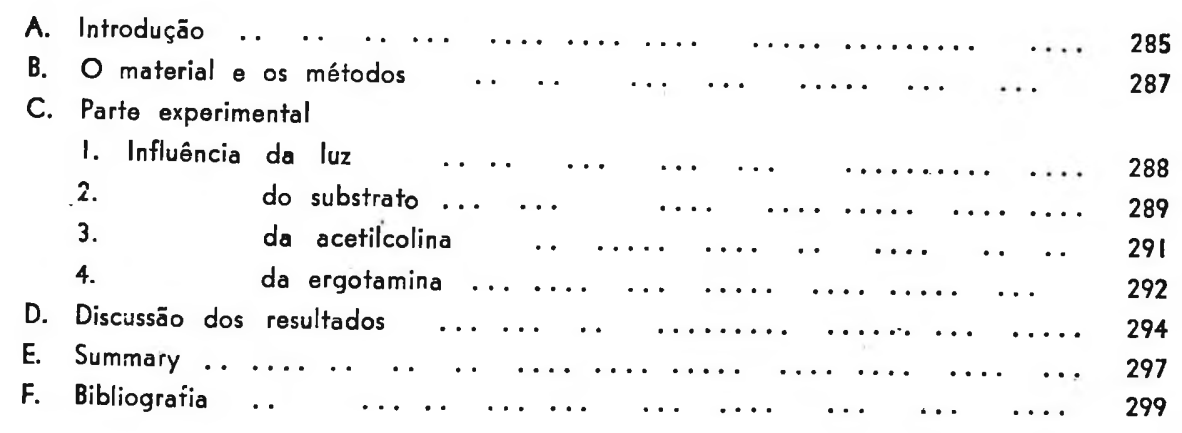

\section{A. \\ Introdução}

O estudo da ação de substâncias melanóforo-ativadoras nos peixes ainda hoje fornece ensejo à discussão, dada a divergência e mesmo a contradição entre os vários pesquisadores. Tal se dá, por exemplo, com relação à ergotamina. Dessa. substância utilizaram-se Spaeth e Barbour (1917) ao tratarem, em $F$ u nd ul us he te rocli t u s, do problema da dupla inervação dos melanóforos (simpática e parasimpática), com o fim de eliminar a ação das fibras simpáticas (concentradoras). Observaram, como consequência do seu emprego (tratava-se no caso do próprio centêio espigado), 
a concentração melanofórica seguida de dispersão incompleta. A adrenalina, que em condições normais é melanóforo-concentradora, adicionada a seguir, causou dispersão máxima. Esta experiência foi repetida por Giersberg (1930, p. 260) que pretende ter elucidado o fato, admitindo que, nas candições experimentais, a adrenalina tinha encontrado como elementos excitaveis apenas as fibras parasimpáticas (dispersoras), visto as simpáticas se acharem inhibidas pela atuação da ergotamina. Este mesmo autor (l. c., p. 263), em $P h \circ x$ in us phoxinus mediante injeções de tartrato de ergotamina ("Gynergène" Sandoz), obteve dispersão dos pigmentos dos melanóforos, seguida de concentração. Aquí a ergotamina agiria primeiro sôbre o simpático, inhibindo-o, e a seguir sôbre os próprios melanóforos diretamente. Dignas de nota são tambem as experiências de Duspiva (1931, pp. 577-579), em Salmo salvelinus Trabalhando com formas muito jovens e "embriões (*) fez gotejar o "Gynergène" sôbre um fragmento de cauda mantido em solução isotônica de $\mathrm{NaCl}$ ou sôbre exemplares com extirpação prévia do saco vitelino. Em ambos os casos obteve forte concentração nos melanóforos. Pela adição de adrenalina, o máximo conseguido foi uma rápida, mas transitória, dispersão. Ultimamente, foi experimentada a influência da ergotamina sôbre melanóforos desinervados. Assim, Bacq (1933), em A m e i u r u s n ebulosus tendo desinervado previamente a porção central da nadadeira caudal de vários indivíduos por mêio de secção do nervo respectivo, submeteu-os à ação do "Gynergène" Afirma o autor ter obtido concentração nos melanóforos da área desinervada e dispersão nos das regiões intatas. A primeira destas conclusões de Bacq foi recentissimamente refutada por Parker (1941). Realisando este autor, tambem em A m eiurus experiências mais completas, assinalou que Bacq fôra vítima de um engano visual relativamente à observação sôbre o comportamento dos melanóforos desinervados sob a ação da ergotamina. Não conseguiu Parker revelar ação alguma dessa substância sôbre êstes melanóforos, embora procedesse de modo idêntico ao de Bacq. No entretanto verificou, tal como êste autor, que a ergotamina opera a dispersão nos inervados. Para Parker êste alcalóide teria ação indireta: excitaria um centro nervoso, cujos elementos, por sua vez, determinariam uma descarga de acetilcolina pelas terminações nervosas sôbre os melanóforos.

Como se vê, são variadas as opiniões àcerca da maneira pela qual a ergotamina age sôbre os melanóforos dos peixes. Resumindo-as, teriamos:

I. Para Spaeth e Barbour a ergotamina é apenas paralisante das fibras simpáticas melanóforo-concentradoras. 2. Para Giersberg, além dessa ação

(*) E' o termo usado pelo autor. 
simpático-inhibidora, há uma outra direta dispersora nos melanóforos. 3. Duspiva, o único a tratar do problema em formas muito jovens e embriões, afirma que a ergotamina é no caso, melanóforo-concentradora. 4. Bacq afirma que o alcalóide concentra os pigmentos dos melanóforos desinervados e dispersa os dos inervados, o que de certo modo lembra a opinião de Giersberg. 5. Parker, finalmente, opina que a droga atua indiretamente sôbre os melanóforos, dispersando-lhes o pigmento, não tendo ação alguma sôbre os mesmos quando se tornam desinervados.

A oportunidade de dispor de algumas traíras (Hoplias malabar icus / muito jovens, material relativamente resistente às operações e experimentações, tornou-me possivel, por sugestão do Prof. P. Sawaya, o estudo da ação da ergotamina sôbre os melanóforos dêsses peixes. Tambem foram experimentadas as influências de outros fatores. Em particular, devido ao fato de se comportarem as formas jovens de certos peixes de modo diverso ao dos adultos, com relação a vários agentes melanoforotrópicos, pareceu-me interessante tentar a verificação do fenômeno no material disponivel. Poucas são as informações na literatura sôbre este pałto. Com efeito, só encontrei as referências de Wenckebach (1886, p. 240) e de Duspiva (1931, p.p. 563-570). O primeiro, em embriōes de Pleuronectes obteve dispersão dos pigmentos expondo os animais à luz e o segundo verificou que embriōes e formas muito jovens de $S$ a $I m$ o s a l velinus e Perca $f \mid$ u $\vee$ i a $t$ i l is dispersavam o pigmento dos melanóforos em presença da luz. Em ambos os casos dêstes autores, dá-se o contrário do que se observa nas fórmas adultas dos peixes em geral, os quais, dêsde que possuam olhos intatos, reagem à luz concentrando os referidos pigmentos (von Frisch 1911; Bacq I. c.; Parker I. c. e outros).

\section{B. \\ O material e os métodos}

Foram utilizadas traíras muito jovens, do comprimento de 6 a $11 \mathrm{~mm}$., com a boca fechada e brânquias ainda não funcionantes. Como ponto de referência nas observações foram escolhidos os melanóforos das regiões: I. nadadeira caudal, 2. região craniana, 3. saco vitelino, 4. flancos do terço médio da cauda. Como índices de expansão e contração destas células valí-me dé algarismos romanos de I-V, à semelhança do que fez Sawaya (1939, p. 62) quando tratou da mudança de côr dos crustáceos: 1 para expansão máxima e $\mathrm{V}$ para a máxima contração. Os animais, provenientes de uma mesma desova, chegaram ao laboratório por especial obséquio dos Drs. Agenor 
Couto de Magalhães e Pedru de Azevedo da Diretoria de Produção Animal, aos quais muito agradeço. Ficaram depositados em pequenos aquários de vidro com água da fonte contendo algumas Elodeas. Daí eram retirados e submetidos à ação dos vários agentes melanóforotrópicos. A ergotamina foi ministrada aos animais sob a forma de tartrato de ergotamina ("Gynergène" Sandoz) numa concentração máxima de $0,05 \%$. A droga foi ora adicionada a uma quantidade conhecida de líquido (água de fonte) onde nadavam os animais, ora êstes eram colocados em uma solução de $0,05 \%$, conteudo total de uma empola de "Gynergéne" O cloridrato de acetilcolina Roche * foi usado em várias dissoluções, como será visto nas tabélas respetivas. Observadas as trairas ainda intatas, procedeu-se a operação para desinervação dos melanóforos de determinada região: seccionando com um golpe nápido de uma tesoura fina, sob a lupa Greenough, totalmente as vértebras e a medula, sempre um milímetro antes da ponta da causa. Os exemplares em que a secção ultrapassava de muito o limite da medula foram desprezados. Após essa operação, a porção distal da cauda arqueava um pou. co, abrindo os lábios da ferida, de onde saía durante algum tempo uma pequena quantidade de sangue que se coagulava em contato com o meio circunjacente. Não obstante, a circulação na área desinervada da cauda, distal ao norte, era preservada à custa dos capilares provenientes da $v$ e $n$ o c a u d a $\mathrm{i} \mathrm{s}$, conforme se vê no esquema publicado recentemente por Sawaya (1942, p. 169, figura). Naturalmente, após a intervenção, os animais passavam por um período de agitação, mas logo depois voltavam ao repouso. A locomoção, como era de esperar-se, ficou bastante prejudicada, deslocando-se os animais com dificuldade e à custa somente das nadadeiras peitorais. Quanto ao mais, mantiveram-se vários dias nêsse estado, em boas condições de vitalidade, permitindo a observação da influência dos vários agentes empregados. Na preparação de ambiêntes claros, cinzentos ou escuros foram utilizados vidros de relógio, cujas faces convexas foram convenientemente pintadas.

\section{C.}

\section{Parte experimental}

I. Influência da luz. As traíras foram colocadas em ambiêntes claros, cinzentos e escuros. Um vidro de relógio pintado de branco e exposto à luz solar (difusa e direta) ou artificial serviu de ambiênte claro. Dois vidros de

(*) Cumpre-me agradecer aos Exmos. Srs. representantes no Brasil dos Produtos Roche de Basilea, pelo fornecimento da acetilcolina, possibilitando estas investigações. 
relógio, tornados translúcidos por uma leve camada de tinta cinzenta, um servindo de tampa, constituiram o ambiênte cinza. Com um dispositivo análogo ao precedente, cobrindo-se as faces convexas dos vidros de relógio com espessa camada de tinta negra, obteve-se o ambiênte escuro. Registraramse os seguintes resultados:

\section{TABELA I}

Influência da luz sôbre os melanóforos de Hoplias malabaricus $(6-8 \mathrm{~mm})$

\begin{tabular}{|c|c|c|c|}
\hline Horas & $\begin{array}{c}\text { claro } \\
\text { (testemunhol }\end{array}$ & cinze & negro \\
\hline 14,42 & 1 & 1 & I \\
14,53 & 1 & IV-V & III-IV \\
15,35 & 1 & IV-V & III-IV \\
16.24 & 1 & $V$ & IV \\
16,27 & 1 & 1 & Exposiçăo à luz I I \\
17,12 & 1 & 1 \\
\hline
\end{tabular}

TABELA $\|$

Influência da luz sôbre os melanb́foros de Hoplias malabaricus $(6-8 \mathrm{~mm})$

\begin{tabular}{|c|c|c|c|}
\hline Horas & $\begin{array}{c}\text { claro } \\
\text { (testemunho) }\end{array}$ & cinza & negro \\
\hline 9,56 & 1 & 1 & 1 \\
10,22 & 1 & II-III & I-II \\
10,40 & 1 & III-IV & I-II \\
\hline
\end{tabular}

Como decorre do exame das tabelas $I$ e $I I$, reagem as traíras jovens à ausência de luz por uma forte contração dos melanóforos, sendo mesmo atingido o estado máximo de contração.

2. Influência do substrato. As experiências foram realizadas principalmente com exemplares medindo 10 a $11 \mathrm{~mm}$. E importante assinalar êsse fato por motivo que será mencionado na discussão dos resultados. Uma única experiência foi feita com animal medindo $7 \mathrm{~mm}$. Foi o seguinte $\circ$ protocolo das experiências com este exemplar de $7 \mathrm{~mm}$.: 
TABELA III

Influência do substrato sôbre os melanóforos de Hoplias malabaricus de $7 \mathrm{~mm}$.

\begin{tabular}{|c|c|c|}
\hline Horas & Ambiênta & $\begin{array}{l}\text { Estado dos } \\
\text { melanóforos }\end{array}$ \\
\hline 10,1 & vidro de relogio comum, à luz solar (difuso) & $\mid 1-1$ \\
\hline 10,3 & idem, forte iluminação & 1 \\
\hline 10.7 & idem, idem & 1 \\
\hline 10,30 & idem, idem & 1 \\
\hline 10,53 & fundos $\theta$ paredes negras, iluminado por cima & I \\
\hline 10,58 & idem, idem & 1 \\
\hline 11,37 & idem, idem & 1 \\
\hline 11,55 & idem, idem & $\begin{array}{c}\text { (lovíssima concen- } \\
\text { tração) }\end{array}$ \\
\hline
\end{tabular}

TABELA IV

Influência do substrato sôbre os melanóforos de Hoplias malabaricus de 10-11 mms. Nos três casos, os animais provindos diretamente do aquário, possuiam melanóforos em gráo IV-V

\begin{tabular}{|c|c|c|c|}
\hline Horas & Fundo branco & Fundo cinzo & Fundo negro \\
\hline II,15 & IV & IV & IV \\
11,35 & IV-V & IV & II \\
11,51 & IV $-V$ & IV & I \\
I2,00 & IV & IV & I \\
\hline
\end{tabular}

\section{TABELA $V$}

Influência do substrato sôbre os melanóforos de Hoplias malaba ricus de $10-11$ mms. Exemplares vindos diretamente do aquário com melanóforos em $\mathrm{V}$.

\begin{tabular}{|c|c|c|c|}
\hline Horas & Fundo branco & Fundo cinza & Fundo negro \\
\hline 14,18 & V & V & V \\
14,45 & V-IV & V-IV & 1 \\
15,10 & V-IV & V-IV & 1 \\
\hline
\end{tabular}

A traíra de $7 \mathrm{~mm}$., conforme se vê na tabela III, colocada em ambiênte canstituido por fundo e paredes negras, com iluminação superior, reagiu com levissima concentração nos melanóforos. Os exemplares de $10-11 \mathrm{~mm}$., submetidos à influência de substratos cinzento e negro, dispersaram fortemente o pigmento nos melanóforos (tabela IV e V). 


\section{Influência da acetilcolina.}

TABELA VI

Influência de acetilcolina sôbre os melanóforos de $H$. malabaricus $(6-8 \mathrm{~mm})$

\begin{tabular}{|c|c|c|c|}
\hline Horas & liquido & ambiênte & melanóforos \\
\hline $\begin{array}{l}11,29 \\
11,40 \\
11,54\end{array}$ & $\begin{array}{c}\text { água de fonte } \\
\text { sol. } 1 \times 10^{-7} \text { acetilc. } \\
\text { em água de fonte } \\
\text { idem }\end{array}$ & $\begin{array}{l}\text { cinzento } \\
\text { idem } \\
\text { idem }\end{array}$ & $\begin{array}{l}v \\
-\end{array}$ \\
\hline
\end{tabular}

\section{TABELA VII}

Influência da acetilcolina sôbre os melanóforos de $H$. malabaricus (6-8 mm)

\begin{tabular}{|c|c|c|c|}
\hline Horas & líquido & ambiênte & melan6foros \\
\hline $\begin{array}{l}11,25 \\
11,45\end{array}$ & $\begin{array}{c}\text { sol. I } 1 \times \text { do for acetilc. } \\
\text { em água de fonte } \\
\text { idem }\end{array}$ & $\begin{array}{c}\text { idem } \\
\text { idem }\end{array}$ & $\mathrm{V}$ \\
\hline
\end{tabular}

TABELA VIII

Influência da acetilcolina sôbre os melanóforos de $H$. malabaricus $(6-8 \mathrm{~mm})$

\begin{tabular}{|c|c|c|c|}
\hline Horas & líquido & ambiênte & melanóforos \\
\hline $\begin{array}{l}14,53 \\
15,35 \\
15,42 \\
15,50 \\
16,12 \\
16,24\end{array}$ & $\begin{array}{l}\text { água de fonte } \\
\text { sol. I X 10-3 acetilc. } \\
\text { em água de fonte } \\
\text { idem } \\
\text { idem } \\
\text { sol. I X 10-2 acetilc. } \\
\text { em água de fonte } \\
\text { idem }\end{array}$ & $\begin{array}{l}\text { cinzento } \\
\text { idem } \\
\text { idem } \\
\text { idem } \\
\text { idem } \\
\text { idem }\end{array}$ & $\begin{array}{c}V \\
V \\
V \\
V-I V \\
- \\
I I I-I I\end{array}$ \\
\hline
\end{tabular}


O cloridrato de acetilcolina, como denotam as tabelas VI, VII e VIII, quando usado em sol. $|\times| 0^{2}$, operou a expansão dos melanóforos.

\section{Influência da ergotamina.}

Como o objetivo principal destas pesquizas era o de verificar a influência da ergotamina sôbre os melanóforos intatos e desinervados, somente nesta série de experiências foram empregadas as traíras operadas.

a) Experiência com animais ilesos.

\section{TABELA IX}

Influência da ergotamina sôbre os melanóforos de H. malabaricus $(6-8 \mathrm{~mm})$

\begin{tabular}{|c|c|c|c|}
\hline Horas & líquido & ambiênte & melanóforos \\
\hline 15,56 & $\begin{array}{c}\text { água de fonte } \\
\text { sol. tartrato de ergo- } \\
\text { tamina em água de } \\
\text { fonte }(0,01 \%) \\
\text { idem } \\
\text { idem }\end{array}$ & $\begin{array}{c}\text { cinzento } \\
16,13\end{array}$ & $\begin{array}{l}\text { idem } \\
\text { idem } \\
\text { idem }\end{array}$
\end{tabular}

\section{TABELA $X$}

Influência da ergotamina sôbre os melanóforos de $H$. malabaricus $(6-8 \mathrm{~mm})$

\begin{tabular}{|c|c|c|c|}
\hline Horas & líquido & ambiênte & melanóforos \\
\hline $\begin{array}{l}17,7 \\
17,13\end{array}$ & $\begin{array}{c}\text { água de fonte } \\
\text { sol. de uma empola } \\
\text { de "gynérgene" } \\
(0,05 \%) \\
\text { idem } \\
\text { idem }\end{array}$ & $\begin{array}{c}\text { cinzento } \\
17,55\end{array}$ & $\begin{array}{l}\text { idem } \\
\text { idem } \\
\text { idem }\end{array}$
\end{tabular}

As tabelas $\mathrm{IX}$ e $\mathrm{X}$ correspondem às observações dos animais intatos sob a ação da ergotamina. Das mesmas se depreende que a referida droga, em ambos os casos, teve ação melanóforo-dispersora.

b) Experiência em que a cauda foi separada do resto do corpo por meio do gálvano-cautério. 


\section{TABELA XI}

Influência da ergotamina sôbre os melanóforos de H. malabaricus (6-8 mm)

\begin{tabular}{|c|c|c|c|}
\hline Horas & líquido & ambiênte & melanóforos \\
\hline 10,3 & água de fonte & cinzento & V \\
\hline 10,9 & \multicolumn{3}{|c|}{ Secção da cauda } \\
\hline 10,12 & $\begin{array}{c}\text { corpo em água de } \\
\text { fonte } \\
\text { cauda em sol. de } \\
\mathrm{NaCl} \text { a } 0,07 \%\end{array}$ & cinzento & $\begin{array}{l}\text { corpo: V } \\
\text { cauda: V-IV }\end{array}$ \\
\hline 10,20 & idem & idem & $\begin{array}{l}\text { corpo: V } \\
\text { cauda: } 1\end{array}$ \\
\hline 10,51 & $\begin{array}{l}\text { corpo e cauda em } \\
\text { sol. de tartrato de } \\
\text { ergotamina a } 0,05 \%\end{array}$ & idem & - \\
\hline 10,56 & idem & idem & $\begin{array}{l}\text { corpo: } \mid 11-11 \\
\text { cauda: } 1\end{array}$ \\
\hline 11,10 & idem & idem & idem \\
\hline
\end{tabular}

A tabela XI mostra que a cauda, separada do corpo e colocada em solução a $0,07 \%$, de $\mathrm{NaCl}$, quando submetida à ação do Gynérgene, não deu margem a que se observasse dispersão nos melanóforos.

c) Em animais operados com desinervação da região terminal da cauda, pelo emprego da ergotamina em sol. a $0,05 \%$, foi observada dilatação melanofórica nas áreas inervadas e nenhuma alteração na região desinervada. Foi o seguinte um dos protocolos obtidos.

TABELA XII

Influência da ergotamina sôbre os melanóforos de $H$. malabaricus $(6-8 \mathrm{~mm})$

\begin{tabular}{|c|c|c|c|}
\hline Horas & líquido & ambiênte & melanóforos \\
\hline $\begin{array}{l}14,24 \\
14,56 \\
15,12 \\
15,14 \\
16,12\end{array}$ & $\begin{array}{l}\text { água de fonte } \\
\text { idem } \\
\text { sol. ergotamino a } \\
0,05 \% \\
\text { idem } \\
\text { idem }\end{array}$ & $\begin{array}{l}\text { cinzento } \\
\text { idem } \\
\text { idem } \\
\text { idem } \\
\text { idem }\end{array}$ & $\begin{array}{l}V \text { (reg. inervada) } \\
V \text { (reg. desinervada) } \\
V \text { (ambas) } \\
V \text { (ambas) } \\
\text { III (reg. inervada) } \\
V \text { (reg. desinervada) } \\
\text { sem alteração }\end{array}$ \\
\hline
\end{tabular}


Desinervando-se, com a técnica já apontada, os melanóforos do extremo caudal, verifica-se (tabela XII) não ter a ergotamina ação sôbre os mesmos no momento próprio em que atua sôbre os demais melanóforos do corpo normalmente inervados.

\section{D.}

\section{Discussão dos resultados}

Bacq e Parker, como já foi mencionado, obtiveram concentração melancfórica pela exposição dos seus animais em ambiênte claro iluminado. $O$ segundo dêsses autores registrou dispersão média em ambiênte cinzento, e, nos indivíduos tornados cegos, observou dispersão máxima nos melanóforos. Pouchet (cit. de Duspiva, I. c., p. 561) foi o primeiro a notar a função pigmento-motora dos olhos, nos peixes, cabendo a von Frisch (1911) porém, a análise pormenorizada da função dêsses orgãos. A luz opera a concentração nos melanóforos de indivíduos adultos de olhos intatos. Já foi visto, na introdução dêste trabalho, que Wenckebach, e Duspiva, pelo que me foi dado ver na literatura consultada, foram os únicos autores que trataram da influência da luz sôbre os melanóforos das formas muito jovens de peixes. Nestas, a reação é inversa a dos adultos, i. é, em presença da luz há dispersão nos melanóforos. Duspiva assinalou também que o escuro provoca concentração. Segundo êsses resultados, a concentração e a dispersão melanofórica são dependentes não só da luz como da idade dos peixes; nas formas muito jovens há dispersão e nos adultos, concentração do pigmento dos melanófuros em presença do referido excitante. Em tal fenômeno, em que se nota $\circ$ antagonismo entre o comportamento dos melanóforos nos jovens e nos adultos, é preponderante o papel dos olhos. von Frisch, por exemplo, nada obteve pela iluminação de larvas de trutas cegas.

Tal reação inversa observada por Wenckebach e Duspiva também existe nos meus animais. No meu material, porém, cumpre dizer, o ambiente cinzento sempre se revelou mais eficazmente concentrador que o escuro.

Duspiva não atribuiu a uma diferença de inervação dos melanóforos dos embriões e formas jovens de $S$ s a I v e l i n u s esta curiosa inversão de reação em presença da luz, porquanto, tal como nos adultos, eles possuem também (p. 579) dupla inervação (simpática e parasimpática), como foi por êle histologicamente demonstrado. É possivel que $\hat{H} \circ p \mathrm{I}$ a s também esteja nêsse caso. Se tal se dér, somente futuras pesquisas talvez poderão 
esclarecer essa curiosa inversão do comportamento dos melanóforos nas formas jovens dos peixes em comparação com o dos adultos.

O substrato, como tem sido estabelecido, é de grande importância na ativação dos melanóforos de peixes adultos. O negro provoca dispersão e o claro ou iluminado por baixo, a concentração do pigmento dos referidos cromatóforos. Para as formas jovens é ainda em Duspiva (1. c.. pp. 563-570) que encontro o único dado disponivel segundo o qual, em $S$ s a I veli nus e em $P$ fluviatilis, o substrato não tem a menor influência sôbre a ativação dos melanóforos. Como se pode inferir das tabelas III, IV e $V$, num caso apenas de um exemplar de $7 \mathrm{~mm}$. obtive levíssima concentração em ambiente negro iluminado por cima. Esse resultado, porém, quando muito poderá servir de indício de que em traíras muito jovens existe reação ao substrato. Todavia, com exemplares de $10-11 \mathrm{~mm}$. registrou-se forte dispersão em substrato negro, não alterando nem o branco inem o cinzento sensivelmente o aspeto dos melanóforos; comportaram-se, pois, tal como os adultos. Quero crer que tal fato tenha corrido por conta do gráu de desenvolvimento das traíras (10-11 mm.). Os melanóforos destas, de fato, já mostravam reações típicas das formas adultas. Por exemplo, antes da experiência, quando as traíras estavam em aquário exposto à luz solar difusa, os melanóforos estavam em nítida dispersão.

Além dos fatores luz e substrato, também substâncias químicas provocam a ativação do pigmento nos melanóforos. Assim, a acetilcolina, tida pelos modernos pesquisadores como a via de que se servem as terminações nervosas para atuar sôbre as referidas células (Parker l. c., p. 167), dispersando-thes o pigmento, determinou em $H$ malabaricus (Tabela VIII), de fato, dispersão melanofórica. Tal resultado concorda com os de Duspiva (1. c., p. 578) obtidos em $S$ a I mo s a I velin us numa fase de vida muito próxima da dos meus animais.

Por sua vez, a ergotamina causou dispersão melanofórica nas traíras experimentadas intatas. Esta droga, porém, não tem ação sôbre os melanóforos de um fragmento de cauda mantido em sol. $0,07 \%$ de $\mathrm{NaCl}$ ou sôbre os de uma região caudalmente situada a uma secção da medula. Tal ação da ergotamina é objeto de discussão por parte dos pesquisadores e uma unidade de vistas está longe de ser alcançada. Os autores que concordam quanto à ação dispersora da substînncia sôbre os melanóforos estão em maioria, mas, mesmos esses divergem âcerca do modo de atuação da droga. Entre os que a empregaram em peixes adultos, destaca-se Giersberg (1. c., p. 263) que, isoladamente, opina pela ação direta da ergotamina sôbre os melanóforos, concentrando-lhes o pigmento. Duspiva (1. c., p. 577-579), em embriões e formas jovens, igualmente, obteve concentração melanofórica. Pela equivalência de idade entre o meu material e o dêste últi- 
mo autor, as observações do mesmo muito se prestam a um confronto com as registradas na presente pesquisa. Esse autor, gotejando o "Gynergène" sôbre um fragmento de cauda mantido em solução isotônica de $\mathrm{NaCl}$, obteve em $S$ a I mo s a I velin u s concentração melanofórica, resultado que, com téanica análoga, não obtive nas traíras experimentadas. Em indivíduos com sacos vitelinos previamente extirpados, Duspiva, pelo mesmo processo do gotejamento do "Gynergène" anotou mais uma vez concentração pigmentar nos melanóforos. Os resultados de minhas experiências (tabs. IX e X) em que os animais foram mantidos em soluções de tartrato de ergotamina a $0,01 \%$ e $0,05 \%$ são contrários, i. é, houve dispersão melanofórica.

E sabido que a regulação da atividade melanofórica não é a mesma em todos os peixes. Parker em 1936 resumiu o estado das pesquisas até então sôbre o assunto, e, posteriormente numerosos trabalhos sôbre a fisiologia dos melanóforos dos peixes foram publicados. Mas, relativamente à regulação mencionada, o que se tem assente até hoje é que há casos em que os melanóforos são controlados por dupla inervação (uma para concentração e outra para dispersão do pigmento), outros em que um só dos dois processos está sujeito ao controle nervoso e, finalmente, outros ainda em que apenas existe regulação hormonal. Assim, por exemplo, $F$ u $n d u l u s ~ h$ e te $\mathrm{r}$ o clitus possue duplo controle nervoso, em $M$ us telus somente a concentração está sujeita à inervação e na lampreia, como nos anfíbios, há somente regulação hormonal (Parker 1936, p. 365). Não me foi possivel a obtenção de dados sôbre o tipo de inervação dos melanóforos de $\mathrm{H} \circ \mathrm{pli}$ a s $\mathrm{m}$ a l a b a ricus Quero crer, porém, que na experiência em que se fez atuar a ergotamina sôbre fragmento de cauda mantido em solução fisiológica estavam os melanóforos fóra de qualquer influência nervosa, valendo pois o resultado como prova de que a droga não atua sôbre os referidos cromatóforos quando desinervados. Quanto aos resultados das experiências com animais operados, com base em von Frisch (1. c., p.p. 333-337), há também fortes indícios de que a secção medular tenha operado a desinervação dos melanóforos posteriormente à mesma. Como, no caso, foi mantida a circulação, os resultados falam ainda mais em favor da opinião de Parker de que a ergotamina não tem ação sôbre os melanóforos desinervados.

Em resumo:

I. Formas jovens de $\mathrm{H} \circ \mathrm{pli}$ a s m a la ba r i c u s dispersam o pigmento dos melanóforos em presença da luz. Comportam-se, assim, de modo inverso ao dos peixes adultos em geral.

2. Um exemplar de $7 \mathrm{~mm}$., mantido em ambiente negro iluminado por cima, apresentou levíssima concentração melanofórica. Exemplares de 10-11 $\mathrm{mm}$. dispersaram fortemente o pigmento dos melanóforos quando colocados 
sôbre fundo negro, comportando-se, portanto, como os adultos dos peixes em geral.

3. A acetilcolina dispersa o pigmento dos melanóforos de $\mathrm{H} \mathrm{m}$ a l a baricus tal como o faz nos demais peixes.

4. A ergotamina tem ação pigmento-dispersora em melanóforos inervados de traíras jovens. Este fato inão está em concordância com o estabelecido por Duspiva em exemplares de Salmo salvelinus de idade equivalente, onde este autor observou concentração melanofórica pela ergotamina.

5. Fragmentos de cauda de $\mathrm{H}$ malabaricus mantidos em solução a $0,07 \%$ de $\mathrm{NaCl}$ e submetidos à ação da ergotamina, não mostraram qualquer reação por parte dos melanóforos.

6. A ergotamina revelou-se ainda inativa com relação a melanóforos situados numa região posterior a uma secção da medula a $1 \mathrm{~mm}$. da ponta da cauda. Tal região foi mantida em boas condições de circulação. Com - seccionamento, pretendeu-se ter obtido a desinervação dos melanóforos referidos. Este resultado vem em apoio ao ponto de vista de Parker sôbre a inatividade da ergotamina relativamente a melanóforos desinervados e é contrário ao de Bacq. que pretende agir a droga sôbre os melanóforos em questão.

\section{E.}

\section{Summary}

Some experiments were performed in order to determine the influence of several excitants on the melanophores of young Hoplias mala b a r i c us the well known Brazilian fish "Traira" The most of the experiments were carried on exemplars measuring 6-8 $\mathrm{mm}$. and melanophore behaviour towards light, background, acetylcholine and ergotamine was tested. To estimate the state of dispersion or concentration of the melanophore pigment, indexes from I to $V$ were chosen, I for maximal dispersion and $\checkmark$ for maximal concentration, according to Sawaya (1939, p. 62) in his studies on the color change in Crustaceans.

To test light influence, the fish larvae wcre firstly observed in watchglasses containing pound water and exposed to difuse sun light. Their melanophore pigment was always in maxima' disper.ion. Afterwards the animals were placed in gray and dark ambients made up by two watch glasses one covering the other and whose convex surfaces were convenientty pain- 
ted. In both ambients pigmental concentration was registered. It was also noted that the gray ambient was more effective than the dark. In adult fishes (see Bacq 1933, p. 387-388; Parker 1941, p. 358, etc.) light causes concentration of the melanophore pigment. In young ones, Wenckebach (1866. p. 2401 and Duspiva (193i, p.p. 563-570) observed inverse reaction towards the same excitant, i. é, melanophoric dispersion. My results agree with these ones and it can be said that also young Hoptias malabaricus has a curious inverse reaction to light.

It is well known that in adult fishes the black background induces melanophoric dispersion. In young $\mathrm{Salmo}$ salvelinus and Perca fluviatilis Duspiva (1. c., p. 568) could not detect any melanophoric reaction towards black background. In my experiments an exemplar 7 $\mathrm{mr}$ long responded to a black background by a very light concentration of their melanophore pigment, neverthless specimens $10-11 \mathrm{~mm}$ long on the same background dispersed the pigment. This reaction, however, similar to that of adult fishes, indicates better that the $10-11 \mathrm{~mm}$ long $\mathrm{H} \circ \mathrm{p} / \mathrm{i}$ a s $\mathrm{m}$ a $\mathrm{a} \mathrm{b}$ a r i c us already respond to background in the adult way.

Acetylcholine chloride when employed in $1 \times 10^{-2}$ solution, causes melanophore dispersion in young $\mathrm{H}$ m a l a b a ricus This result agrees with many other authors'researches.

Ergotamine tartrate ("Gynergène" Sandoz) has recently been used by Parker (1941, pp. 164-166) in A meiurus ne bulosus when this author refuted Bacq's conclusions (1933, pp. 388) concerning the action of ergotamine on denervated melanophores. Parker admits that ergotamine is only an indirect excitant of inervated melanophores by inducing them to disperse their pigment. In young $\mathrm{Salmo}$ salvelinus Duspiva (1. c. pp. 577-579) observed melanophoric concentration with ergotamine. Dropping "Gynergène" in an isotonic solution of $\mathrm{NaCl}$ containing tail fragments of young $\mathrm{Sa} I \mathrm{~m}$ o s a I velin us Duspiva registered also concentration of the melanophore pigment. Young $\mathrm{H} \quad \mathrm{m}$ a $\mathrm{la} \mathrm{b}$ a $r \mathrm{i} c$ us submerged in solutions of $0,01 \%$ and $0,05 \%$ of ergotamine tartrate showed melanophore dispersion instead of concentration as observed by Duspiva in $\mathrm{S} s$ a I veI i n u s By dropping "Gynergène" in a $0,07 \% \mathrm{NaCl}$ solution containing tail fragments of young $\mathrm{H} \quad \mathrm{malab}$ a ric u s no reaction was detected in the melanophores. This experiment indicates that ergotamine has no action on denervated melanophores, according to Parker's point of view. In animals whose spinal cord was cut one millimeter before the tail tip, ergotamine tartrate was seen to be unable to activate the pigment in the melanophores of the region posterior to the cut. Based on von Frisch's work (19||, pp. 333-337) there is some reason to suppose that those melanophores we- 
re denervated by the operation. In this case the circulations in the denervated region was preserved. This experiment also produces evidence of the inalterability of denervated melanophores by ergotamine.

\section{F. \\ Bibliografia}

BACQ, Z. M. 1933, The action of ergotamine on the chromatophores of the cattish E (Ameiurus nebulosus). Biol. Bull. v. 65, n.a 3, pp. 387-388. Lancaster, Pa.

DUSPIVA, F. 1931, Beiträge zur Physiologie der Melanophoren von Fischembryonen. Akademie der Wissenschaften in Wien. Matematik-naturwiss. Klasse, Abteil. I, v. 140. c. 7. pp. 553-596, t. 9. Wien.

V. FRISCH, K. 1911, Beiträge zur Physiologie der Pigmentzellen in der Fischhaut. Pflüger's Archiv f. d. gesam. Physiol., v. 138, f. 6-9, pp. 319-387, t. 1-5. Berlin.

GIERSBERG, H. 1933, Der Farbwechsel der Fische. Zeitschrift. vergl. Physiologie, v. 13. f. 2, pp. 258-279. Berlin.

PARKER, G. H. 1936, Neurohumor controlling Chromatophores. Cold Spring Harbour Symposia on Quantitative Biology vol. IV, pp. 358-370. Cold Spring Harbour, L. I. New York.

- 1941. The response of catfish melanophores to ergotamine. Biol. Bull., v. 8I, n.: 2. pp. 163-167. Lancaster, Pa.

SAWAYA. P. 1939, Sôbre a mudança de côr nos crustáceos. Bol. Fac. Phil. Sc. e Letras, XIII, Zoologia n: 3, pp. 3-109. S. Paulo.

- 1942. The tail of a fish larva as respiratory organ. Nature, n. 3771, p. 169. London.

SPAETH, R. \& BARBOUR, H. G. 1917, The action of epinephrin and Ergotoxin upon single, physiological isolated cells. Journ. Pharm. Exp. Therapeutics, v. 9, pp. 431-440. Baltimore.

WENCKEBACH, K. F. 1886, Beiträge zur Entwicklungsgeschichte der Knochenfische. Arch. f. mikroskp. Anat. u. Entwick.-Gesch., 28, pp. 225-250, t. XVI e XVII. Bonn - Berlin. 

